\title{
PHOTOGRAMMETRIC TECHNIQUES FOR 3-D UNDERWATER RECORD OF THE ANTIQUE TIME SHIP FROM PHANAGORIA
}

\author{
M.O. Zhukovsky ${ }^{a^{*}}$, V.D. Kuznetsov ${ }^{\mathrm{b}}$, S.V. Olkhovsky ${ }^{\mathrm{b}}$ \\ a ANO Contemporary Technologies in Archaeology and History, Moscow, Russia (mzhukovsky@mail.ru). \\ ${ }^{\mathrm{b}}$ Institute of Archaeology RAS, Moscow, Russia (ptakkon@yandex.ru).
}

KEY WORDS: Fanagoria, underwater excavations, antique time ship, photogrammetry, 3-D model, orthophoto

\begin{abstract}
:
Phanagoria - the largest known ancient Greek settlement on the territory of Russia is situated on the Taman peninsula on the southern side of the Taman bay. The unique feature of the site is that about $1 / 3$ of the settlement of Phanagoria is currently flooded by waters of the Taman bay due to the transgression of the Black sea level since antiquity. In 2012 in the course of underwater prospection of the Taman bay a wooden ship buried under the $1.5 \mathrm{~m}$ thick bottom sediments was discovered in situ. The unique feature of the ship is excellent preservation of its wooden parts, which makes it one of the few finds of this kind ever made on the territory of Russia. This paper presents a case-study of application of photogrammetry technique for archaeological field documentation record in course of underwater excavations of the Phanagorian shipwreck. The advantages and possible underwaterspecific constraints of automated point cloud extraction algorithm which was used in the research are discussed. The paper gives an overview of the practical aspects of the workflow of photgrammetry technique application at the excavation ground: photo capture procedure and measurement of control points. Finally a resulting 3-D model of the shipwreck is presented and high potential of automated point cloud extraction algorithms for archaeological documentation record is concluded.
\end{abstract}

\section{INTRODUCTION}

Recent years are marked by a substantial increase in application of photogrammetric techniques in archaeological field practice. It becomes more and more often that photogrammetry successfully competes more traditional (in terms of application in archaeology) laser-scanning for true 3-D digital record of excavated objects. This trend seems to be boosted by a development of automated software algorithms of dense point cloud extraction when a "blackbox" software tool is able to produce a result comparable to one obtained through rigorous manually controlled processing (Drap, 2012).

In the years 2011-2012 the Phanagorian archaeological expedition has started wide implementation of photogrammetric techniques combined with high-precision laser measurements in the process of archaeological excavations and field documentation record. The aim of photogrammetry application is to provide a comprehensive 3-D record of excavated archaeological objects at every step of field research. Photogrammetric tools are used for creating precise 3-D textured virtual models of any excavated object (archaeological strata, pits, architectural remains, burials, etc.) at consecutive stages of its disassembly as archaeological exploration is in most cases irreversibly destructive (Zhukovsky, 2013).

This paper presents a case-study of the use of photogrammetry for archaeological field documentation record in course of underwater excavations of the Phanagorian shipwreck which have been conducted in the year 2012 .

\section{THE ARCHAEOLOGICAL CONTEXT}

\subsection{The archaeological complex of Phanagoria}

Phanagoria - the largest known ancient Greek settlement on the territory of Russia is situated on the Taman peninsula on the southern side of the Taman bay (Kuznetsov, 2011; Tsetskhladze, 2002). Founded by the Ionian greeks from Teos (Asia Minor) in 540-s B.C. the settlement was continuously inhabited till XI A.D. In the classical period Phanagoria is considered to have been the capital of so-called Asian, or Cimmerian, Bosporus. The city had flourished till the very end of the first century B.C. when the wars of Mithridates VI against Rome exhausted the Kingdom of Pontus. During the first millennium A.D. the territory of Phanagoria shrinks but it still remains one of the major settlements of the region as a part of Byzantine empire and later - Bulgar and Khazarian state. Last khazarian inhabitants have abandoned Phanagoria at the beginning of the XI-th century A.D.

The contemporary archaeological complex of Phanagoria consists of the fortified multilayer settlement - acropolis, surrounded by vast necropolis, both covering an area of about 860 hectares. The unique feature of the site is that about $1 / 3$ of the settlement of Phanagoria in its widest extent dating from the classical period is currently flooded by waters of the Taman bay due to the transgression of the Black sea level since antiquity. Archaeological survey shows that the shift of the shore line have not been abrupt, finds from undisturbed cultural layers currently covered by water display a continuous slow movement of the ancient sea edge towards contemporary shore (Tsetskhladze, Brandon, 2002).

According to a recent research, combining multispectral satellite imagery analysis, bathymetry data from hydrographic echo sounder and profiler and mapping of underwater archaeological finds, the ancient shore line in its 6-5 centuries B.C. state lies at a distance of 240-260 $\mathrm{m}$ from current sea edge.

\subsection{The Phanagorian shipwreck}

In 2012 in the course of underwater prospection of the Taman bay a wooden ship buried under the $1.5 \mathrm{~m}$ thick bottom sediments was discovered in situ (Kuznetsov, Olkhovskiy, 2013; Olkhovskiy, 2012). The find was made at a distance of $135 \mathrm{~m}$ from the present-day shore of the Taman bay at a depth of $0,9-1,0 \mathrm{~m}$ within the flooded part of the territory of the settlement of Phanagoria (fig. 1). The location of the find makes the ship one of the important keystones in reconstruction of the temporal change of the shore line during the existence of the site. Another unique feature of the ship is excellent preservation 


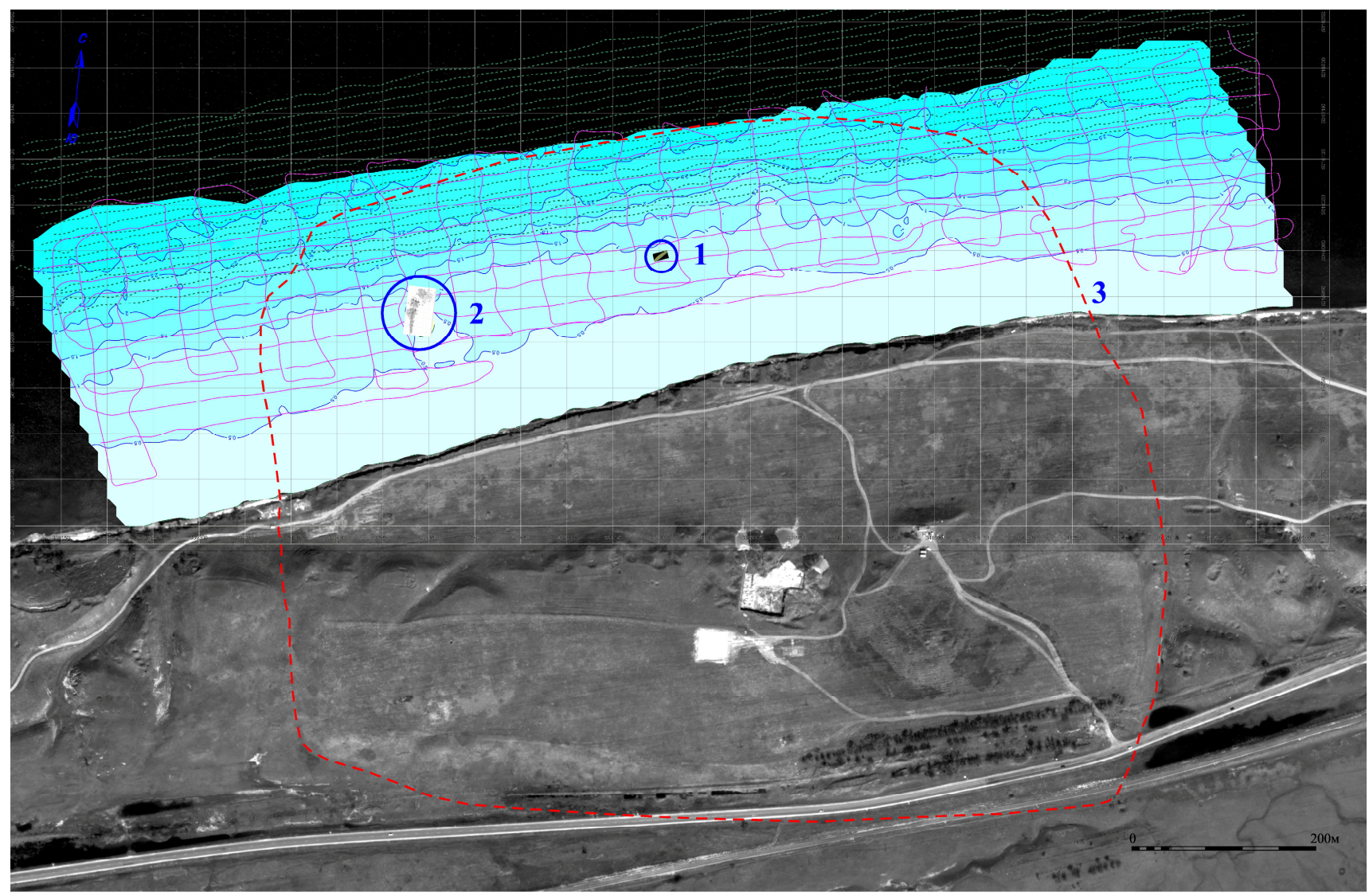

Figure 1. The ancient city of Phanagoria from space: 1 . The Phanagorian shipwreck, 2 . The excavated remains of the pier of the Roman period, 3. The city limits marked by cultural layers at their maximum extent. Background - WorldView-1 high resolution imagery.

of its wooden parts, which makes it one of the few finds of this kind ever made on the territory of Russia (fig. 2). Warm salty water is a hazardous environment for any organic remains and in most cases ancient shipwrecks are marked solely by their ceramic or stone loads and, occasionally, metal anchors. The Phanagorian ship is one of the lucky exceptions - the accumulation of silt sediments covering the find was very fast, probably as a result of a heavy storm, and preserved the wooden hull of the ship from dissolution. The position of the find seems to indicate that it was buried just at or very close to the sea edge.

The Phanagorian ship had no cargo on board at the moment of its wreckage - only a few ceramic vessels were found within its body. This fact makes the find itself the major clue to its

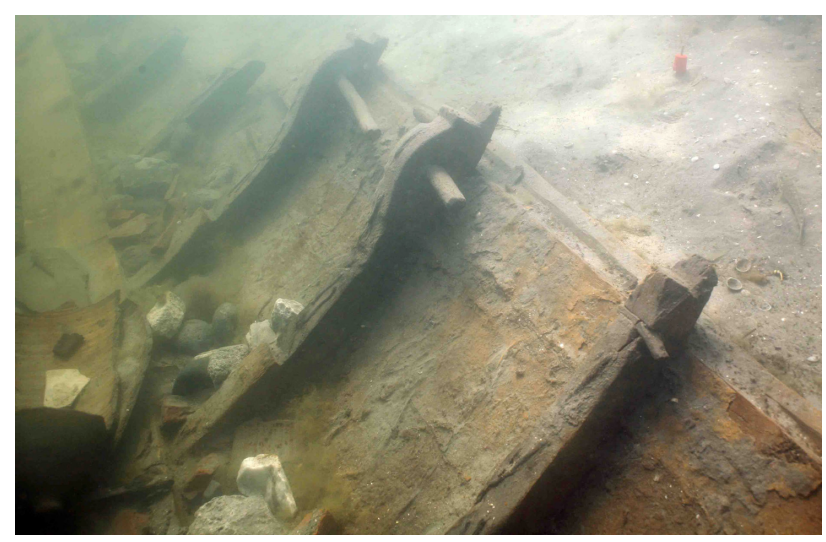

Figure 2. The Phanagorian ship. A detail of the ship's hull. chronological attribution. While wooden material of the find was sampled for $\mathrm{C}^{14}$ and dendro dating analysis (still being processed at the moment of preparation of this paper) this data requires a reliable historical context for verification. The dendro scale for the region is still incomplete while $\mathrm{C}^{14}$ dating is able to provide only a wide confidence interval. Thus, complete excavation of the find was essential for its correct identification, chronological attribution and reconstruction.

\subsection{The excavation and documentation record strategy}

However, complete excavation of the wreck pose a substantial risk to the condition of the ship remains exposing them to an aggressive environment. Yet another risk comes from the shallow sea depth at the find spot where the whole water column is affected by waves and current. Any storm would have destroyed the unearthed artifact. Taking these factors into consideration, the excavation and field documentation record, which is the most time-consuming, should be conducted in a very limited time span. As far as the method of rapid yet detailed and precise archaeological field documentation record is concerned photogrammetry seems to fit best the role.

\section{PHOTOGRAMMETRY TECHNIQUE AND ITS FIELD APPLICATION}

\subsection{The software}

The Agisoft PhotoScan (www.agisoft.ru) software was used for point cloud extraction procedure. PhotoScan tool provides an 
automated workflow for point extraction and matching, generation of triangular mesh and its texturing. A user is able to control only general parameters of procession which is in most cases quite sufficient for obtaining a geometrically correct 3-D model of high quality. Some manual fine tuning of the algorithm is available within the software through image masking and false points elimination - correctly used these tools are able to refine a resulting model.

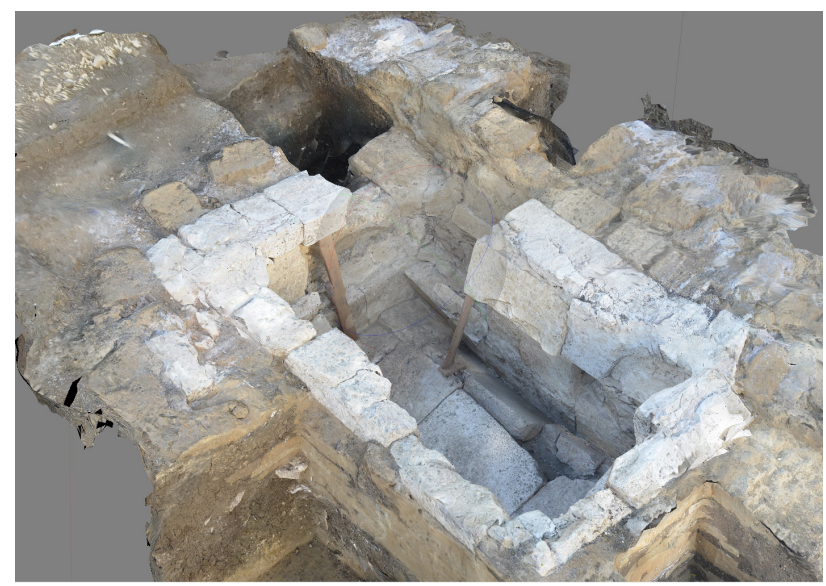

Figure 3. A photogrammetric 3-D model of the central burial of the Bour-gora mound, necropolis of Phanagoria.

The major weakness of 'blackbox' automated photogrammetry tools is the uncertainty of a result, when a user doesn't know what he will get until a model is assembled. In other words, algorithm is very dependant on the quality and, majorly, consistency of source data. Minor incompleteness of photo coverage of a modeled object leads to a general fail. This fact is mostly overweighed by time and human resources effectiveness of an automated point cloud extraction when 3-D modeling can be conducted in real-time just in course of ongoing excavations.

\subsection{Test applications and possible underwater constraints}

An automated point cloud extraction algorithm provided by the PhotoScan software had been successfully applied at a number of terrestrial excavation grounds at Phanagoria. The most prominent among them are the excavations of Bour-gora mound (fig. 3) conducted in 2011 (Zhukovsky, 2013). While the results, which have been obtained in course of terrestrial applications, proved high efficiency of automated photogrammetry implementation for archaeological field documentation record, still, three major issues concerning its underwater use were uncertain:

- how optical distortions caused by water and camera port will affect an automated point extraction and matching algorithm (presuming no manual matching);

- how optical 'noise' caused by moving interfering objects (like small fish, little portions of grass, and, majorly, suspension contained in water) will affect both point extraction and resulting triangular mesh of the object;

- how low transparency of water and lack of light (compared to terrestrial conditions) will affect both point matching and texturing of the model.

Additionally several site-specific technical difficulties were to be resolved. Shallow depth at the excavation site $(1 \mathrm{~m}$ to the seabed and about $3 \mathrm{~m}$ to the deepest point within the excavation ground) made the whole water column affected by waves and turbulence. In such conditions an operator with a photo camera is unable to take a stable position, while any touch of the bottom or sides of the excavation pit cause an influx of feculence in the water.

\subsection{Fieldwork}

The excavation ground had the dimensions of $20 \times 6 \mathrm{~m}$ with $2 \mathrm{~m}$ maximum depth below the seabed (nearly $3 \mathrm{~m}$ from the water surface). The excavated shipwreck has the total length of $15,1 \mathrm{~m}$ with a maximum width of $2,5 \mathrm{~m}$ by the middle. The water transparency at best conditions didn't exceed $3 \mathrm{~m}$, so no single image of the find in its full extent could be made. Permanent water turbulence and current provided a very short time span of 2-3 hours within which the excavated ship stayed clear from grass and sand.

Prior to photo capture a set of control points (more then 300 in total) was marked over the ship hull by pins with color heads arranged at an irregular grid. The control points were put to geometrical extremums of the object and keypoints of its frame. The coordinates of the control points were measured by total station situated on the shore. A $3 \mathrm{~m}$ pole was used - just enough to reach the deepest spots of the excavation ground. The measurement required 3 people 'operating' the pole: one at the bottom to position the end of the pole over the control point, second, standing at 2 long planks put across the excavation ground, - to control the pole's inclination from the vertical and third - managing the communication between them. The primary goal of control points was to georeference the resulting 3-D model of the ship, making it measurable. But also a grid of control points was expected to provide a frame of distinct marks suitable for manual point matching in case an automated algorithm would fail.

Photographs were captured by a boxed DSLR full-frame camera from both straight (off nadir, parallel to the sea level) and oblique angles. The shot distance didn't exceed $2 \mathrm{~m}$ as the majority of photos were taken at $0,5-1 \mathrm{~m}$ distance from the object.

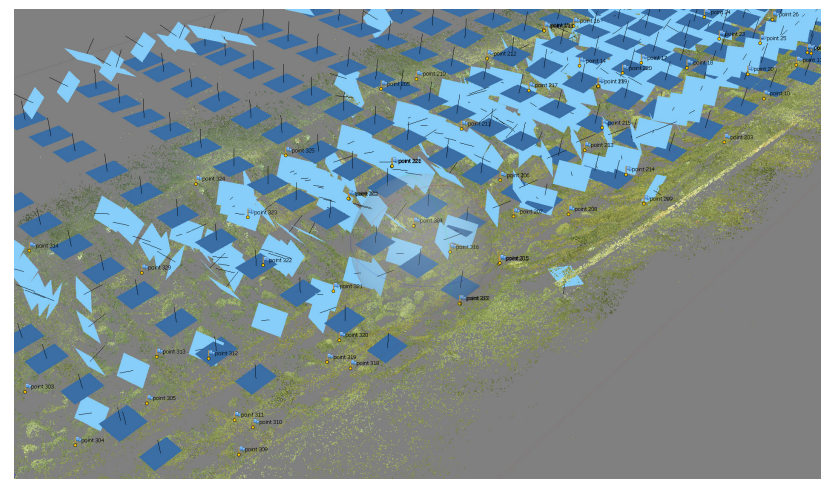

Figure 4. A detail of the point cloud extracted from the photoset. Color squares mark reconstructed camera positions:

blue - for off nadir photos, cyan - for oblique photos.

The complete and regular coverage of the object by off nadir series of photographs was achieved by stable positioning of the boxed camera at a small platform moving along 2 parallel 8 meter long metal rails placed across the excavation ground. The platform was positioned just under the water surface to provide a maximum possible shot distance. A platform was manually moved along the rails with shots being taken at equal distances between camera positions. After a complete line was captured the construction was shifted along the side of the excavation 


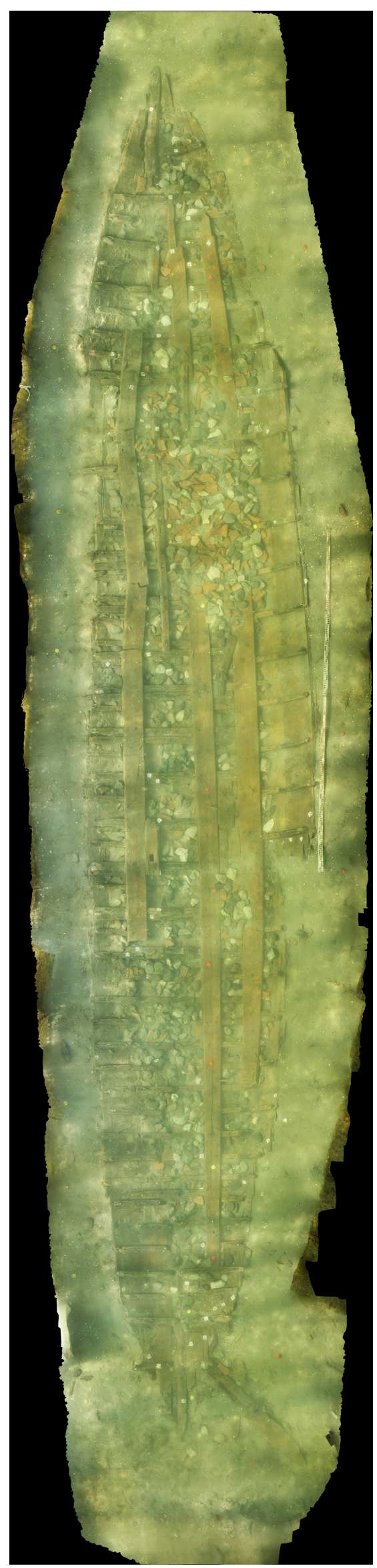

Figure 5. Orthophoto mosaic of the Phanagorian ship. ground to make a consecutive line. Camera positions were not measured and recorded. It took 3 sets of images to be taken at various 'grid' sizes to achieve optimum spacing between camera positions that will provide a sufficient overlap of the photos. The set which was finally used for photogrammetric procession consisted of 33 lines with 10-12 images in each line.

An additional, nearly equal in number, set of images was captured from oblique angles at free positions along the sides of the ship and its keel line.

Immediately after the record has been completed the ship was conserved to prevent its destruction from warm salty water environment.

\subsection{Photogrammetric procession}

There were 663 images in total finally selected for procession with PhotoScan software. About 700.000 effective points were extracted and matched by the automated algorithm (slightly more then 1000 per photo). Proper point matching was performed by the software only from the densest off nadir photo set where distance between camera positions did not exceed 0,4 $0,5 \mathrm{~m}$. The photo sets with sparser grid stepping failed automated matching. The number of false points caused by water turbulence and moving interfering objects was around 5\% of the total. These points were eliminated manually prior to mesh generation. The size of the triangular mesh calculated from the point cloud was limited to 500.000 faces. A more dense TIN will provide a smother final model but hardware constraints had to be taken into account.

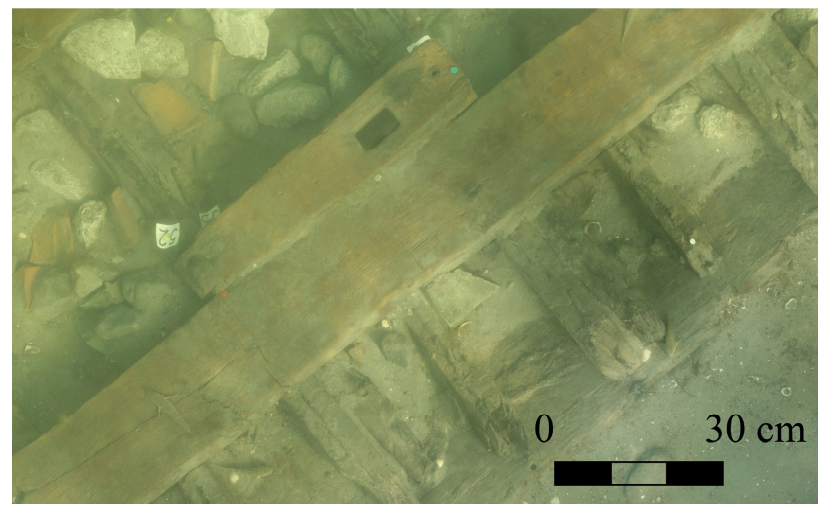

Figure 6. Orthophoto mosaic of the Phanagorian ship. A detail.

Control points were used to correctly orient the resulting model in space and put it into scale. Finally, the orthophoto mosaics of the ship in various projections, unobtainable in real underwater conditions, were assembled from raw imagery. The use of 3-D model geometry as a reference for orthophoto rectification has eliminated optical distortions of the images. The best quality 560 Mpix orthophoto was generated from 'the top' orientation of the model as it coincided with the highest quality photoset captured from off nadir angle.

\section{CONCLUSIONS}

The case-study presented in this paper demonstrates the high efficiency of photogrammetric techniques application for underwater archaeological field documentation record. An automated point cloud extraction algorithm implemented in Agisoft PhotoScan software has proved its capability to create a high quality and precise 3-D models of excavated underwater 
objects even in unfavorable conditions - low water transparency and lack of light. Compared to its terrestrial application, a successful result of automated photogrammetric procession is achieved through extensive photo coverage of the modeled object (with 50-60\% overlap of the images), use of high quality camera optics and presence of distinct control points with measured coordinates.

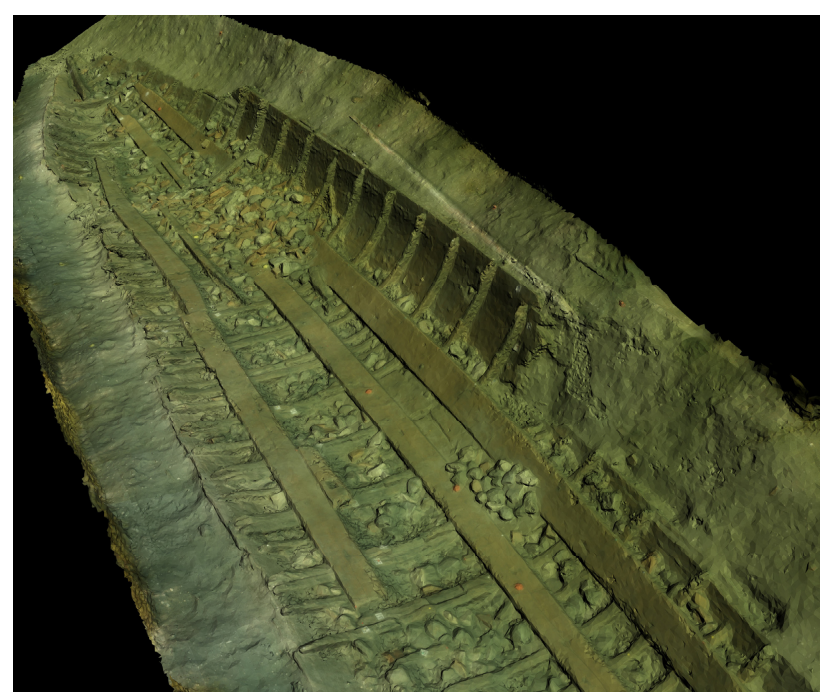

Figure 7. A shaded render of the ship's 3-D model.

Application of photogrammetry enabled the research team to create a comprehensive and precise virtual 3-D replica of the uncovered underwater find in one week time span of field record. The model of the Fanagorian shipwreck, along with its presentational and educational value, is the main source of data for scientific research of the find and elaboration of its further conservation strategy and procedure.

\section{REFERENCES}

Canciani, M. et al. Low Cost Digital Photogrammetry for Underwater Archaeological Survey and Artefact Isertion. The Case Study of the Dolia Wreck in Secche della MeloriaLivorno-Italia. The International Archives of the Photogrammetry, Remote Sensing and Spatial Information Sciences, Vol. XXXIV, Part 5/W12, pp. 95-100.

Coates, J. F., 2000. The Athenian Trireme (2nd ed.). Cambridge University Press.

Drap, P., 2012. Underwater Photogrammetry for Archaeology. In: Special Applications of Photogrammetry. http://www.intechopen.com/books/special-applications-ofphotogrammetry/ underwater-photogrammetry-for-archaeology.

Kuznetsov, V., 2011. Phanagoreia - die Hauptstadt des asiatischen Bosporos. In: Altertümer Phanagoreias. Bd. 1. Phanagoreia, Kimmerischen Bosporos, Pontos Euxeinos. Göttingen.

Kuznetsov, V., Olkhovskiy, S., 2013. Recent Underwater Researches at Phanagoria // Paper presented at $17^{\text {th }}$ Symposium on Mediterranean Archaeology. Moscow.

Olkhovskiy, S., 2012. The Phanagorian shipwreck: first attempt to identify // Paper presented at $13^{\text {th }}$ International Symposium on Boat and Ship Archaeology. Amsterdam.

Tsetskhladze, G., Brandon, C., 2002. Notes on the Survey of the Submerged Remains of Phanagoria in the Taman Peninsula. In: Ancient West \& East. Vol. 1.1.

Tsetskhladze, G., 2002. Phanagoria: Metropolis of Asiatic Bosporus. In: Archaeology Without Frontiers. Athens.

Zhukovksy, M., 2013. Application of Comprehensive Computer Technique for Field Excavation and Reconstruction of the Bourgora Mound of the Phanagorian Necropolis (in Russian). In: Virtual Archaeology (nondestructive methods of prospections, modeling, reconstructions). Proceedings of the First International Conference held at the State Hermitage Museum. 4-6 June 2012. St. Petersburg. 